\title{
Vertical circulation and thermospheric composition: a modelling study
}

\author{
H. Rishbeth ${ }^{1}$, I. C. F. Müller-Wodarg ${ }^{1,2}$ \\ ${ }^{1}$ Department of Physics and Astronomy, University of Southampton, Southampton SO17 1BJ, UK \\ ${ }^{2}$ Atmospheric Physics Laboratory, Department of Physics and Astronomy, University College London, \\ 67-73 Riding House Street, London W1P 7PP, UK
}

Received: 18 August 1998 / Revised: 2 November 1998 / Accepted: 10 November 1998

\begin{abstract}
The coupled thermosphere-ionosphere-plasmasphere model CTIP is used to study the global threedimensional circulation and its effect on neutral composition in the midlatitude F-layer. At equinox, the vertical air motion is basically up by day, down by night, and the atomic oxygen/molecular nitrogen $\left[\mathrm{O} / \mathrm{N}_{2}\right]$ concentration ratio is symmetrical about the equator. At solstice there is a summer-to-winter flow of air, with downwelling at subauroral latitudes in winter that produces regions of large $\left[\mathrm{O} / \mathrm{N}_{2}\right]$ ratio. Because the thermospheric circulation is influenced by the highlatitude energy inputs, which are related to the geometry of the Earth's magnetic field, the latitude of the downwelling regions varies with longitude. The downwelling regions give rise to large F2-layer electron densities when they are sunlit, but not when they are in darkness, with implications for the distribution of seasonal and semiannual variations of the F2-layer. It is also found that the vertical distributions of $\mathrm{O}$ and $\mathrm{N}_{2}$ may depart appreciably from diffusive equilibrium at heights up to about $160 \mathrm{~km}$, especially in the summer hemisphere where there is strong upwelling.
\end{abstract}

Key words. Atmospheric composition and structure (thermosphere - composition and chemistry) ·

Ionosphere (ionosphere - atmosphere interactions)

\section{Introduction}

It has long been known that the F2-layer shows seasonal and semiannual anomalies that depart from normal solar-controlled behaviour. They are described in some detail by Yonezawa and Arima (1959) and by Torr and Torr (1973); for historical details and theories of origin,

Correspondence to: $\mathrm{H}$. Rishbeth see Rishbeth (1998). Briefly, the winter or seasonal anomaly exists if (daytime) $\mathrm{NmF} 2$ is greater in winter than in summer, the semiannual anomaly exists if $\mathrm{NmF} 2$ is greater at equinox than at solstice.

From their study of the increase of F2-layer electron density just after sunrise, Rishbeth and Setty (1961) suggested that the seasonal anomaly is caused by changes in chemical composition, specifically in the ratio of the concentrations of atomic oxygen and molecular nitrogen. Such changes of the $\left[\mathrm{O} / \mathrm{N}_{2}\right]$ ratio would also account for the anomaly in noon $N \mathrm{mF} 2$. At that time, the $\left[\mathrm{O} / \mathrm{N}_{2}\right]$ ratio at F-region heights was almost unknown and any seasonal change was just a hypothesis. However, Johnson (1964) and King (1964) suggested by qualitative arguments that the atomic/ molecular ratio is influenced by summer-to-winter transport, and some years later Duncan (1969) advanced the idea that the composition changes are caused by global-scale vertical and horizontal winds associated with a worldwide thermospheric circulation. Shimazaki (1972) showed that large-scale vertical motions are more effective than turbulence or eddy diffusion in changing thermospheric composition.

Duncan's (1969) idea that the composition changes are caused by a global circulation in the thermosphere was eventually fully confirmed by global modelling of the thermosphere (Fuller-Rowell and Rees, 1983), and the seasonal composition changes were detected experimentally. Millward et al. (1996a) showed that the seasonal composition changes, taken in conjunction with the seasonal changes of solar zenith angle, can broadly account for the existence of both annual and semiannual variations in $N \mathrm{mF}$. This has been confirmed by a comprehensive modelling study by Zou et al. (in preparation 1999).

The present work describes the first detailed computational study of the vertical circulation and the related variations of the neutral $\left[\mathrm{O} / \mathrm{N}_{2}\right]$ ratio. Section 2 presents the theory, Sect. 3 gives necessary details of the CTIP model, Sects. 4 and 5 describe the computed patterns of the horizontal and vertical variations of the vertical 
winds and the neutral $\left[\mathrm{O} / \mathrm{N}_{2}\right]$ ratio, Sects. 6 and 7 conclude the report.

\section{Theory}

\subsection{Height scales}

In this study the symbol $h$ stands for real height in kilometres and $Z$ for 'reduced height' measured in units of the pressure scale height $H$. The total pressure $p$ on a given pressure-level $Z$ is given by

$p(Z)=1.04 \exp (1-Z)[\mathrm{Pa}]$

The base level $h_{0}$, which is $80 \mathrm{~km}$ in CTIP, is denoted by $Z=1$ (not $Z=0$ ) so the parameters are linked by the equations

$Z=1+\int_{h_{0}}^{h} \frac{\mathrm{d} h}{H}$

$h(Z)=h_{0}+\int_{1}^{Z} H \mathrm{~d} Z$

in which the integration extends from the base level $\left(h_{0}=80 \mathrm{~km}, Z=1\right)$ up to the height in question. As these heights are referred to later in the work, lists of heights and temperatures, for typical March conditions at midlatitudes for solar activity $F_{10.7}=100$, are given in Table 1.

\subsection{Barometric and divergence velocity}

The vertical wind velocity in the thermosphere (taken to be positive upward) can be expressed as the sum of two components (Dickinson and Geisler, 1968; Rishbeth et al., 1969):

$U_{\mathrm{Z}}=W_{\mathrm{B}}+W_{\mathrm{D}}$

The 'barometric' component in Eq. (4) represents the rise and fall of constant pressure-levels, due to thermal expansion or contraction, and is given by

$W_{\mathrm{B}}=\left(\frac{\partial h}{\partial t}\right)_{p}$
Consider first a simple one-dimensional motion, in which the expansion or contraction causes purely vertical up or down winds, with no horizontal flow. The pressure at any point in the atmosphere is just the weight of the column of air above that point, so the amount of air above a given pressure-level is constant (assuming that the vertical acceleration $\ll$ the gravitational acceleration $\mathrm{g}$ ) and the air does not move with respect to the pressure-levels.

The real three-dimensional thermosphere contains both vertical and horizontal motions. Since the neutral air is neither produced nor destroyed, upward wind must be accompanied by horizontal divergence of air at great heights, and by horizontal convergence of air at the bottom of the thermosphere; the opposite situation applies to downward wind. To balance this divergence and convergence, the air moves vertically through the pressure-levels with a velocity called the 'divergence velocity'. This velocity is related to the rate of change of pressure of a given cell of air, and is given by

$W_{\mathrm{D}}=-\frac{1}{\rho \mathrm{g}} \frac{\mathrm{d} p}{\mathrm{~d} t}$

To evaluate $W_{\mathrm{D}}$, it is necessary to compute the horizontal divergence

$\Pi=\frac{\partial\left(n U_{x}\right)}{\partial x}+\frac{\partial\left(n U_{y}\right)}{\partial y}$

where $x, y$ represent horizontal directions, $U_{\mathrm{x}, \mathrm{y}}$ are the winds in those directions, and $n$ is the neutral gas concentration. Then the flux of air through any given pressure-level $Z$, equal to $n W_{\mathrm{D}}$, must balance the heightintegrated divergence above that pressure-level, so that

$W_{\mathrm{D}}=\frac{1}{n} \int_{Z}^{\infty} \Pi \cdot H \mathrm{~d} Z$

from which $W_{\mathrm{D}}$ may be numerically computed (the integration runs from the height in question to the top of the thermosphere, $Z=15$ in the model). Note that the apparently simpler way of computing vertical velocity, by solving the vertical component of the vector equation of motion, does not work, the reason being that the equation is completely dominated by gravity and the vertical pressure-gradient force, and effectively reduces to the hydrostatic equation $-\partial p / \partial h=\mathrm{g}$ (Rishbeth et al., 1969). Given the limitations of the numerical computa-

Table 1. Pressure-levels, real heights and temperatures for typical midlatitude conditions at $F_{10.7}=100$

\begin{tabular}{|c|c|c|c|c|c|c|c|c|c|c|c|c|}
\hline Pressure-level $Z$ & 1 & 3 & 5 & 7 & 8 & 9 & 10 & 11 & 12 & 13 & 14 & 15 \\
\hline \multicolumn{13}{|l|}{ Noon, 12-LT } \\
\hline Height $h(\mathrm{~km})$ & 80 & 91 & 103 & 127 & 143 & 166 & 197 & 235 & 277 & 321 & 365 & 411 \\
\hline Molar mass $M$ & 28.8 & 28.7 & 27.6 & 25.0 & 23.3 & 21.6 & 19.8 & 18.3 & 17.2 & 16.6 & 16.3 & 16.2 \\
\hline \multicolumn{13}{|l|}{ Midnight, 00-LT } \\
\hline Height $h(\mathrm{~km})$ & 80 & 91 & 103 & 127 & 142 & 163 & 190 & 222 & 256 & 293 & 331 & 369 \\
\hline
\end{tabular}


tion, all other terms are relatively too small (of order 1/ 1000 of gravity) to be evaluated with sufficient accuracy.

The circulation is completed by a return flow at lower levels in the thermosphere, with much smaller wind speeds corresponding to the higher gas density. No attempt is made here to model the return flow.

\subsection{Effect of vertical motion on composition}

For our purposes, chemical composition is specified by the neutral $\left[\mathrm{O} / \mathrm{N}_{2}\right]$ concentration ratio. A simple extension of the argument of Garriott and Rishbeth (1963) (see Appendix, Eq. 17) shows that, at any fixed pressure-level $Z$, this ratio is not changed by barometric motion. The divergence velocity, however, does change the $\left[\mathrm{O} / \mathrm{N}_{2}\right]$ ratio at a fixed pressure-level (Rishbeth et al., 1987). The general rules that relate F2-layer behaviour to vertical air motions may be summarized thus:

a. The electron density $N$ depends on the $\left[\mathrm{O} / \mathrm{N}_{2}\right]$ ratio, by day and to some extent by night. This is because (as is well known) the electron production rate depends on the $\mathrm{O}$ concentration, the electron loss rate depends on the concentrations of molecular gases (mainly $\mathrm{N}_{2}$ ).

b. Barometric motion (positive or negative $W_{\mathrm{B}}$ ) changes the $\left[\mathrm{O} / \mathrm{N}_{2}\right]$ ratio and the mean molar mass at a fixed height, but not at a fixed pressure-level.

c. Upwelling (positive $W_{\mathrm{D}}$ ) decreases the $\left[\mathrm{O} / \mathrm{N}_{2}\right]$ ratio and increases the mean molar mass, at a fixed pressure-level, so tends to decrease the electron density $N$. Downwelling (negative $W_{\mathrm{D}}$ ) has the opposite effect.

The distinction between $W_{\mathrm{B}}$ and $W_{\mathrm{D}}$ is perhaps more important in theory than in practice. The computations show that at F2-layer heights, $W_{\mathrm{B}}$ is in general smaller than $W_{\mathrm{D}}$, and no great difference would result from using the total vertical velocity $W_{\mathrm{B}}+W_{\mathrm{D}}$ instead of just $W_{\mathrm{D}}$. Nevertheless, the distinction is worth preserving because of the different local time variations: $W_{\mathrm{D}}$ is essentially upward by day, downward by night, while $W_{\mathrm{B}}$ is upward in the morning when the thermosphere is heating up and expanding, and downward in the evening and night when the thermosphere is cooling and contracting.

\subsection{The P-parameter}

Above the turbopause at $100 \mathrm{~km}$ height, there is little or no eddy mixing, so each major constituent has its own pressure scale height $H$ and the composition varies with height. The major neutral constituents at F2-layer heights are atomic oxygen (atomic mass 16) and molecular nitrogen (molecular mass 28), their scale heights being in the ratio 28:16. If these gases are in diffusive equilibrium, it is easily seen that their partial pressures $p$ vary with height in such a way that

$28 \ln p(\mathrm{O})-16 \ln p\left(\mathrm{~N}_{2}\right)=$ const.
Recalling that pressure is proportional to concentration $\times$ temperature, it follows from Eq. (9) that the parameter $P$ defined by the equation

$P=28 \ln [\mathrm{O}]-16 \ln \left[\mathrm{N}_{2}\right]+12 \ln T$,

(square brackets indicating gas concentrations) is height-independent in a diffusively separated thermosphere. The term $12 \ln T$ (where $12=28-16$ ) appears in Eq. (10) because, in general, the temperature $T$ varies with height. This $P$-parameter was introduced by Rishbeth et al. (1987) (although, in that paper, $P$ was defined with opposite signs on the right hand side of Eq. (10) and an arbitrary constant was added to make the numerical values positive).

Only changes of $P$ are important, the absolute values have no significance. A change of +1 unit in $P$ implies a change of $+3.6 \%$ in $[\mathrm{O}]$, or a change of $-6.2 \%$ in $\left[\mathrm{N}_{2}\right]$, or a change of $+8.3 \%$ in $T$, or a combination of these. At a fixed pressure-level, it may be more useful to discuss how $P$ varies with changes of the $\left[\mathrm{O} / \mathrm{N}_{2}\right]$ ratio. Assuming no change of temperature, it is found that (for example) a change of $P$ by +1 unit represents an increase of $\left[\mathrm{O} / \mathrm{N}_{2}\right]$ ratio of $4.6 \%, 5.6 \%$, or $6.1 \%$ when the $\left[\mathrm{O} / \mathrm{N}_{2}\right]$ ratio is (respectively) 1,5 , or 20 - this being the range of values of $\left[\mathrm{O} / \mathrm{N}_{2}\right]$ ratio applicable to the noon F2 peak (Zou et al., in preparation 1999).

If the thermosphere is static, or has only barometric motion, $P$ is independent of height at all levels where $\mathrm{O}$ and $\mathrm{N}_{2}$ are diffusively distributed with their own scale heights. In empirical models of the thermosphere, such as MSIS (Hedin, 1986), diffusive equilibrium is assumed to exist above $120 \mathrm{~km}$, even though the composition may vary horizontally. How far this situation holds in the dynamic thermosphere, as modelled by CTIP, is discussed in Sect. 5.

\section{Modelling with the coupled thermosphere-ionosphere- plasmasphere (CTIP) model}

\subsection{Main features of CTIP}

The modelling was done with the coupled thermosphereionosphere-plasmasphere model (CTIP) described by Fuller-Rowell et al. (1996), Millward et al. (1996b) and Field et al. (1998). The parameters are computed at 15 pressure-levels, $Z=1-15$, spaced at vertical intervals of one scale height (see Table 1), and on a global grid with spacing $2^{\circ}$ in latitude and $18^{\circ}$ in longitude.

The model runs used for this study assume moderate solar activity, corresponding to $F_{10.7}=100$. Some comparisons are made with model runs for higher solar activity, $F_{10.7}=180$. Fairly quiet geomagnetic conditions $(K p=2+)$ are assumed throughout. The results shown are for December and June solstices and March equinox, though model runs for other months are available. Further details of the runs are given by Zou et al. in preparation (1999).

The results are mainly concerned with midlatitudes, i.e. the zones between the magnetic equatorial region and the auroral ovals. In the equatorial zone, within 
about $20^{\circ}$ of the magnetic equator, F2-layer behaviour is strongly influenced by the low-latitude system of electric fields, but this zone is not important to the present work because the modelled electrodynamic drift, taken from Richmond et al. (1980), is found to have little effect on the neutral composition (see Sect. 5).

\subsection{Magnetic geometry}

CTIP uses a geomagnetic field model with offset poles, situated at $81^{\circ} \mathrm{N}, 78^{\circ} \mathrm{W}$ and $74^{\circ} \mathrm{S}, 126^{\circ} \mathrm{E}$. The poles are surrounded by the eccentric auroral ovals, which are belts about $10^{\circ}$ wide that receive energy from electric fields and energetic particles generated by magnetospheric processes. These energy inputs are specified in CTIP by the Tiros particle precipitation model (FullerRowell and Evans, 1987) and by a statistical model of the polar electric field (Foster et al., 1986) that extends down to $65^{\circ}$ magnetic latitude. For present purposes, these inputs are assumed not to change with the time of year. The low-latitude boundaries of the ovals, which play an important part in determining the thermospheric circulation, lie at about $75^{\circ}$ magnetic latitude at noon and $66^{\circ}$ magnetic latitude at midnight. Because of the offsets of the magnetic poles, the corresponding geographic latitudes vary with longitude, by about $\pm 8^{\circ}$ in the north and $\pm 15^{\circ}$ in the south.

\section{Maps of winds, divergence velocity and $\mathrm{O} / \mathrm{N}_{2}$ ratio}

\subsection{Maps}

Figure 1 shows global snapshots at 12 UT of the temperature field and horizontal wind field at the top of the thermosphere, for December, March and June. The patterns at the F2-peak are very similar. At equinox, both temperature and wind fields are broadly symmetrical about the equator, with 'highs' and 'lows' of temperature (and pressure) centred near local times $16 \mathrm{LT}$ and $04 \mathrm{LT}$ respectively, corresponding to longitudes $60^{\circ} \mathrm{E}$ and $120^{\circ} \mathrm{W}$. At solstice the afternoon 'high' moves to the summer hemisphere, the early morning 'low' to the winter hemisphere. At high latitudes, the details of the wind field depend on the positions of the magnetic poles and the auroral ovals. At $12 \mathrm{UT}$, as portrayed in Fig. 1, the South magnetic pole is in the evening sector $(20 \mathrm{LT})$ and the North magnetic pole in the morning sector (07 LT).

On the left, Fig. 2 shows latitude/local time maps of the vertical divergence velocity at pressure-level $Z=12$ (as defined in Eq. 1, the real height being about $277 \mathrm{~km}$, near the daytime F2 peak) at longitude $0^{\circ}$ in December, March and June. On the right of Fig. 2 are $\mathrm{O} / \mathrm{N}_{2}$ ratios for the same conditions. Notice that the maxima or minima of the $\left[\mathrm{O} / \mathrm{N}_{2}\right]$ ratio and of $W_{\mathrm{D}}$ do not always coincide, as discussed in Sects. 4.2 and 6.

Look first at the plots for March equinox. The patterns of $W_{\mathrm{D}}$ and $\left[\mathrm{O} / \mathrm{N}_{2}\right]$ are almost symmetrical about the geographic equator, which at this longitude

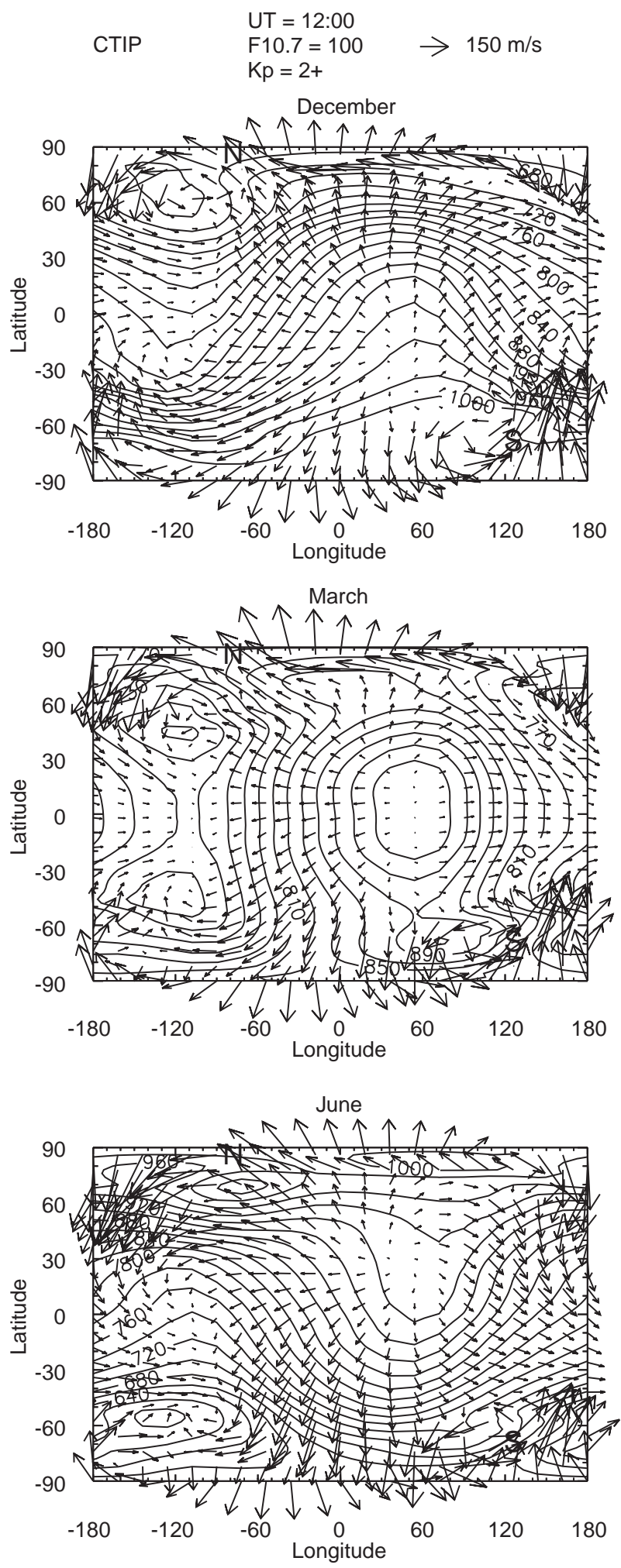

Fig. 1. Horizontal wind and temperature fields for 12 UT at pressure-level $Z=15$, in geographic latitude and longitude. Letters $N, S$ mark the positions of the magnetic poles. The minimum and maximum temperatures are as follows: December, 606 and $1073 \mathrm{~K}$; March, 664 and $955 \mathrm{~K}$; June, 606 and $1023 \mathrm{~K}$. The arrow indicates a wind speed of $150 \mathrm{~m} \mathrm{~s}^{-1}$ 
CTIP
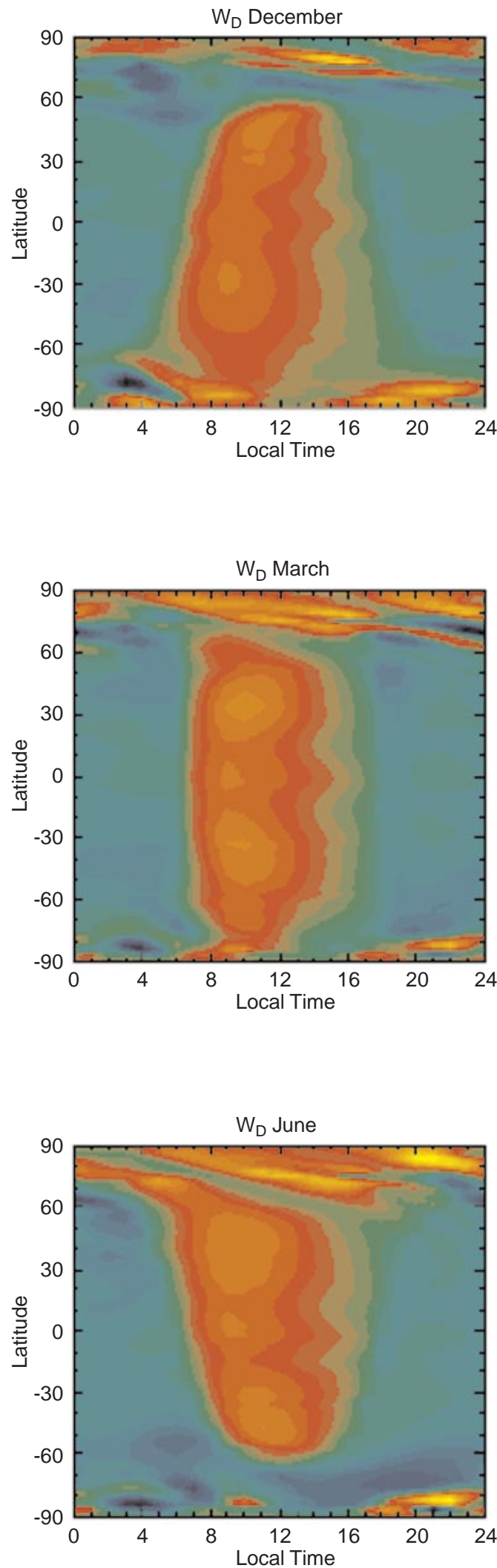
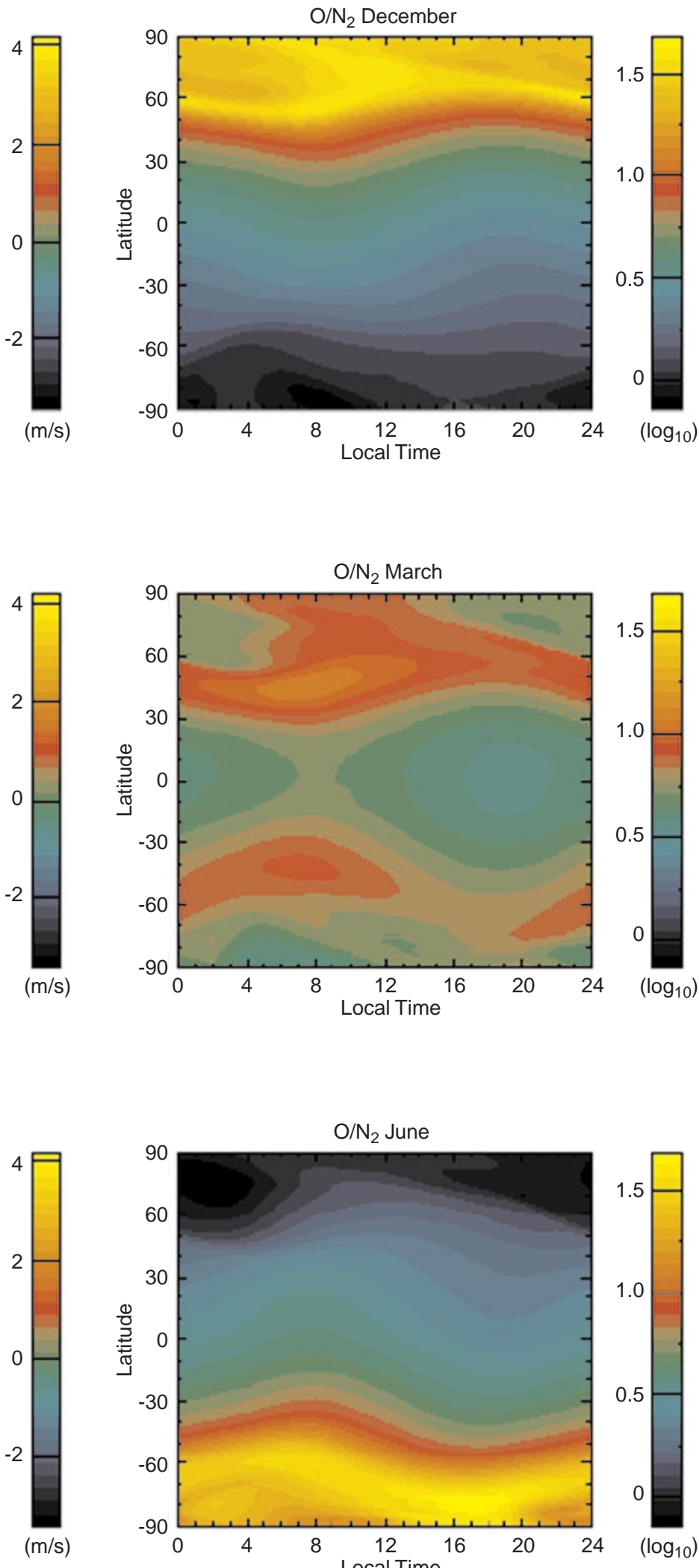

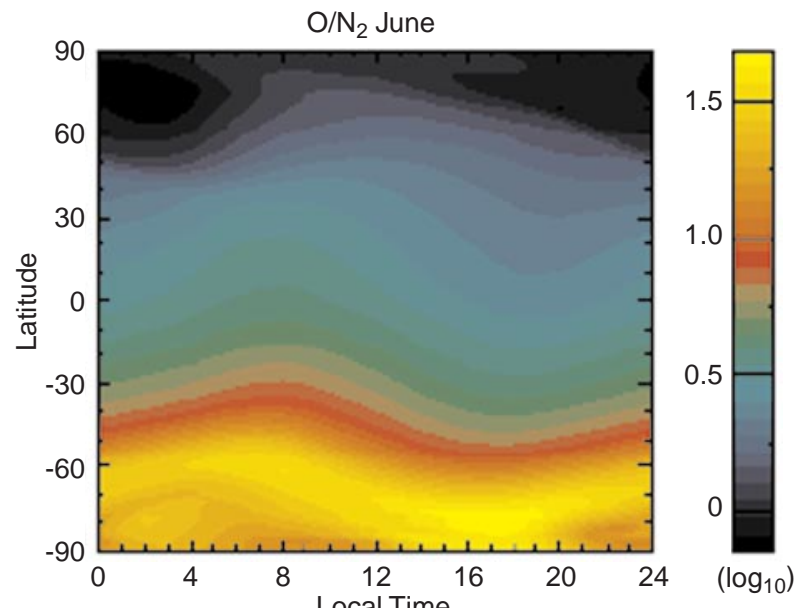

Fig. 2. Left: contour maps in latitude and local time of vertical divergence velocity $W_{\mathrm{D}}$ at pressure-level $Z=12$, longitude $0^{\circ}$ in December, March and June. Right: contour maps in latitude and local time of $\left[\mathrm{O} / \mathrm{N}_{2}\right]$ ratio at pressure-level $Z=12$, longitude $0^{\circ}$ in December, March and June 
coincides with the magnetic equator. $W_{\mathrm{D}}$ is basically up by day and down by night, with fairly sharp boundaries at dawn and dusk. The $\left[\mathrm{O} / \mathrm{N}_{2}\right]$ ratio likewise has a basically day-to-night variation. Now look at the March wind field in Fig. 1. At the equator, the wind vectors lie almost east-west, so the prevailing (24-hour average) meridional wind is very small (it is actually $0-3 \mathrm{~m} \mathrm{~s}^{-1}$ at the equator, depending on longitude) so there is no net north-to-south transport of air at these heights.

Now look at the December plots in Figs. 1 and 2. At the equator there is a prevailing meridional wind of 25 $30 \mathrm{~m} \mathrm{~s}^{-1}$, which varies with longitude. Again, $W_{\mathrm{D}}$ is basically up by day and down at night, with the boundary roughly following the sunrise/sunset line; but there is now a strong downwelling region at $60^{\circ}-$ $75^{\circ} \mathrm{N}$ at most local times, with narrow bands of upwelling in the auroral ovals. But the December $\left[\mathrm{O} / \mathrm{N}_{2}\right]$ ratio differs dramatically from the March pattern, with a dominant winter/summer gradient and a weak local time variation. The June plots in Fig. 2 are almost mirror images of the December plots, with minor differences due to the magnetic geometry. As in the March case, there is complex structure in the vicinity of the auroral ovals in both hemispheres.

If solar activity is increased from $F_{10.7}=100$ to $F_{10.7}=180$, the patterns of neutral gas temperature and $W_{\mathrm{D}}$ are very much the same as in Figs. 1 and 2, with the numerical values of $T$ and $W_{\mathrm{D}}$ multiplied by a factor of 1.6.

The $0^{\circ}$ meridian represents an average situation, being not very close to the magnetic pole in either hemisphere. The equatorward boundaries of the northern and southern auroral ovals are at high geographic latitudes $\left(77^{\circ} \mathrm{N}\right.$ and $\left.80^{\circ} \mathrm{S}\right)$. At other longitudes the same basic description of $W_{\mathrm{D}}$ and $\left[\mathrm{O} / \mathrm{N}_{2}\right]$ ratio holds, though with appreciable differences due to the geographic latitudes of the magnetic poles, as now discussed in Sect. 4.2.

\subsection{Latitude profiles}

The line diagrams of Fig. 3 show in more detail how the divergence velocity $W_{\mathrm{D}}$, the $\left[\mathrm{O} / \mathrm{N}_{2}\right]$ ratio and peak electron density $N \mathrm{mF} 2$ vary with latitude at longitudes $90^{\circ} \mathrm{E}$ and $90^{\circ} \mathrm{W}$. Again, the figure is drawn for pressurelevel $Z=12$ which is near the daytime F2 peak. The black blocks mark the northern and southern boundaries of the auroral ovals. First, notice in the plots of $W_{\mathrm{D}}$ that moderate upwelling (about $1 \mathrm{~m} \mathrm{~s}^{-1}$ ) occurs at all seasons at middle and low latitudes. Downwelling at subauroral latitudes occurs even in summer but is much more prominent in winter (though at $90^{\circ} \mathrm{E}$, the southern downwelling zone at $60^{\circ} \mathrm{S}$ is quite weak even in June winter). At auroral latitudes, upwelling takes place at all seasons, usually more strongly in winter and equinox than in summer.

In 'near-pole' longitudes, namely the North Atlantic and Australasian sectors, the noon auroral ovals are at moderate geographic latitudes, $66^{\circ}-76^{\circ} \mathrm{N}$ at $90^{\circ} \mathrm{W}$ and $60^{\circ}-68^{\circ} \mathrm{S}$ at $90^{\circ} \mathrm{E}$ (in Fig. 3, towards the right of the $90^{\circ} \mathrm{W}$ plots and towards the left of the $90^{\circ} \mathrm{E}$ plots). In winter, the lower boxes in Fig. 3 show that downwelling is confined to narrow zones between the auroral ovals and the sunlit midlatitude thermosphere, where there is no strong input of energy to oppose downwelling. The middle boxes in Fig. 3 show that these latitude zones contain high $\left[\mathrm{O} / \mathrm{N}_{2}\right]$ ratios of $15-30$ (i.e. 1.2 to 1.5 on the $\log _{10}$ scale). Because these zones are in sunlight, the high $\left[\mathrm{O} / \mathrm{N}_{2}\right]$ ratios give rise to large values of $N \mathrm{mF} 2$.

In 'far-from-pole' longitudes, namely the South American/Antarctic sector at $90^{\circ} \mathrm{W}$ and the Asian/ Arctic sector at $90^{\circ} \mathrm{E}$ (in Fig. 3, towards the left of the $90^{\circ} \mathrm{W}$ plots and towards the right of the $90^{\circ} \mathrm{E}$ plots), the situation is quite different. The noon auroral oval straddles the geographic poles, and upwelling due to auroral input is seen only at the very edges of the plots. Downwelling in winter takes place over zones about $20^{\circ}$ wide, equatorward of the ovals and beyond the reach of winter sunlight, which are thus devoid of any solar and auroral energy input that could cause upwelling. These zones of strong winter downwelling are particularly deep, with values of $W_{\mathrm{D}}$ down to $-2 \mathrm{~m} \mathrm{~s}^{-1}$, more negative than in near-pole longitudes, and $\left[\mathrm{O} / \mathrm{N}_{2}\right]$ ratios as high as 50 (i.e. 1.7 on the $\log _{10}$ scale). But, even though the $\left[\mathrm{O} / \mathrm{N}_{2}\right]$ ratios are larger than in the "nearpole' longitudes, $N \mathrm{mF} 2$ is very small because of the absence of sunlight. As discussed by Millward et al. (1996a), Rishbeth (1998) and Zou et al. in preparation (1999), factors such as these largely determine the worldwide distribution of the seasonal and semiannual variations in $\mathrm{NmF} 2$.

The $\left[\mathrm{O} / \mathrm{N}_{2}\right]$ latitude profiles have less structure than the profiles of $W_{\mathrm{D}}$. This suggests that the redistribution of air by the horizontal wind has a smoothing-out effect. The strong zonal winds at winter subauroral latitudes seem to play a particular part in enhancing the $\left[\mathrm{O} / \mathrm{N}_{2}\right]$ ratio. At middle and low latitudes, the relation between $N \mathrm{mF} 2$ and the $\left[\mathrm{O} / \mathrm{N}_{2}\right]$ ratio is complicated by the latitude variations of solar zenith angle and, in the equatorial zone, by the influence of the electric fields that produce the 'Appleton anomaly'. This question is discussed further by Zou et al. in preparation (1999).

\section{Cross sections of divergence velocity and $\boldsymbol{P}$-parameter}

As explained in Sect. 2.4, the parameter $P$ is independent of height in a thermosphere in diffusive equilibrium. The latitude/height cross sections of Fig. 4 show that this situation does not always apply. At the bottom of the thermosphere (pressure-levels 1-3, corresponding to $80-91 \mathrm{~km}), P$ is small because there is little atomic oxygen. Above level $Z=3$ at $91 \mathrm{~km}$, the photochemical processes cause an upward increase of $[\mathrm{O}]$, so $P$ increases upward. Above about $Z=7$ at $127 \mathrm{~km}$, diffusion becomes dominant over photochemistry, but diffusive equilibrium is not fully established until about $Z=9$ at about $166 \mathrm{~km}$, and in some places even higher.

The March plots in Fig. 4 show that the distribution of $P$ is almost symmetrical about the geographic equator, which at this longitude $\left(0^{\circ}\right)$ coincides with the magnetic equator. Results for other longitudes, where 
CTIP
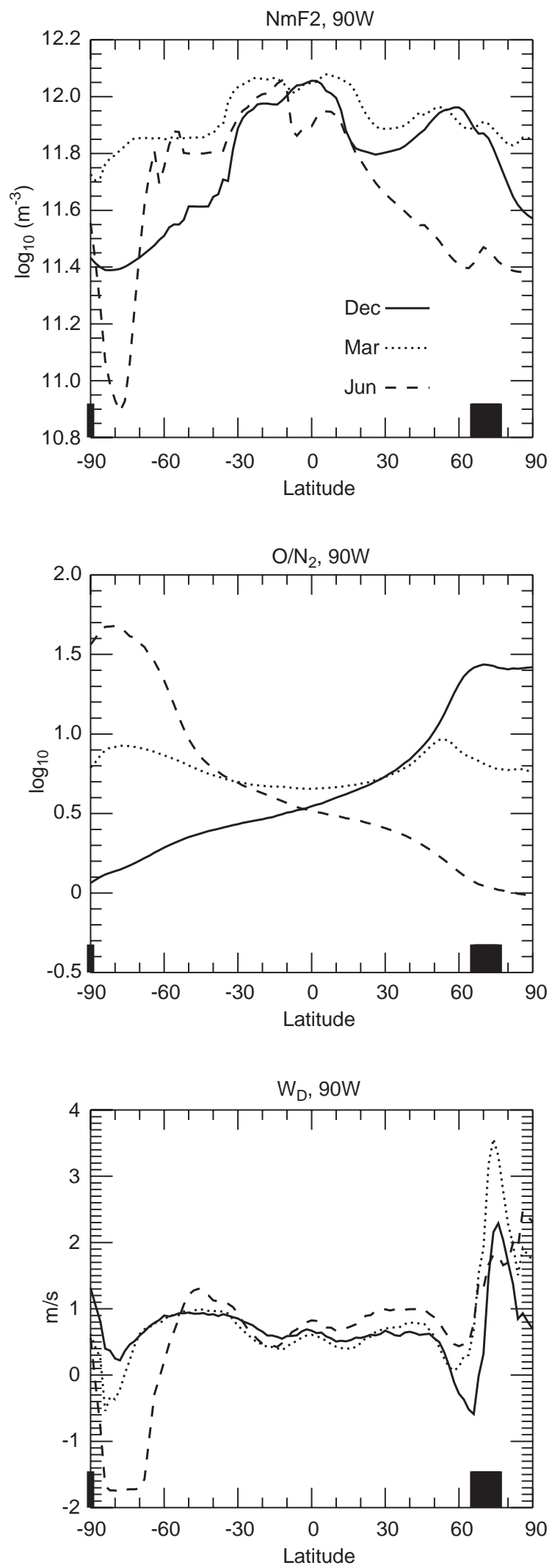

Fig. 3. Noon $W_{\mathrm{D}}, N \mathrm{mF} 2$ and $\left[\mathrm{O} / \mathrm{N}_{2}\right]$ ratio versus geographic latitude at longitudes $90^{\circ} \mathrm{E}$ and $90^{\circ} \mathrm{W}$, for December (solid curves), March (dotted curves) and June (dashed curves). Black blocks show the northern and southern auroral ovals. The northern oval at
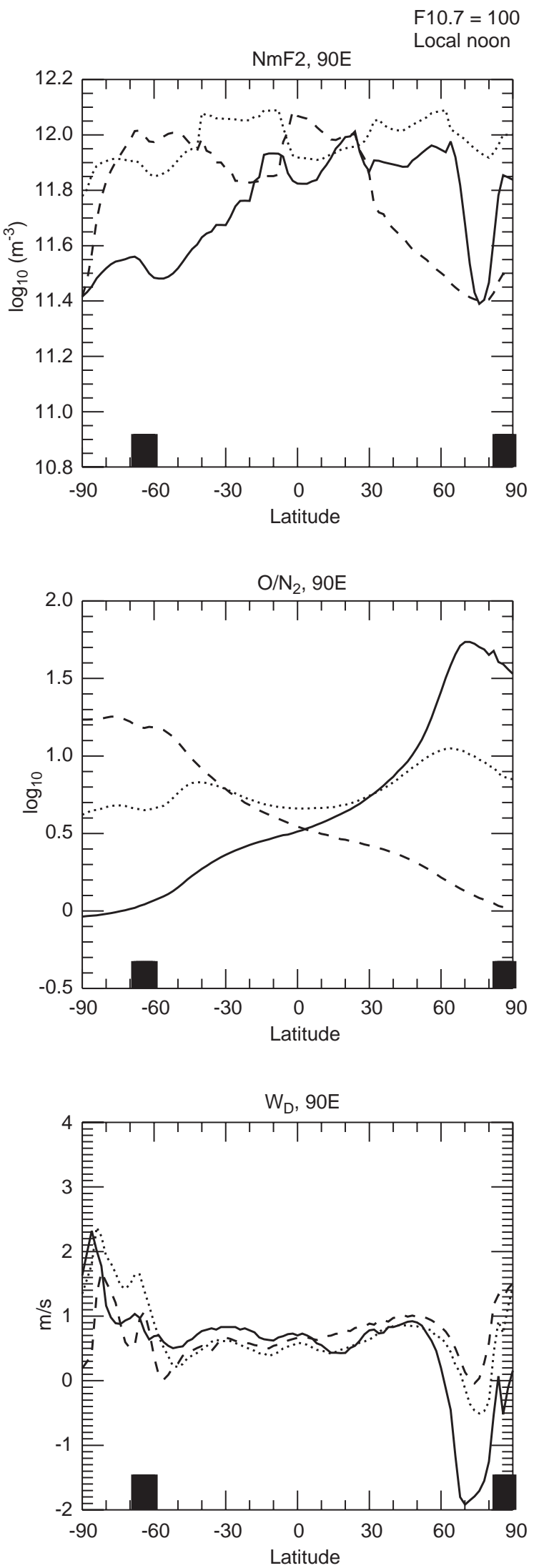

$90^{\circ} \mathrm{E}$ and the southern oval at $90^{\circ} \mathrm{W}$ extend over the geographic pole into the opposite (midnight) meridian, so their full extent is not shown 
CTIP
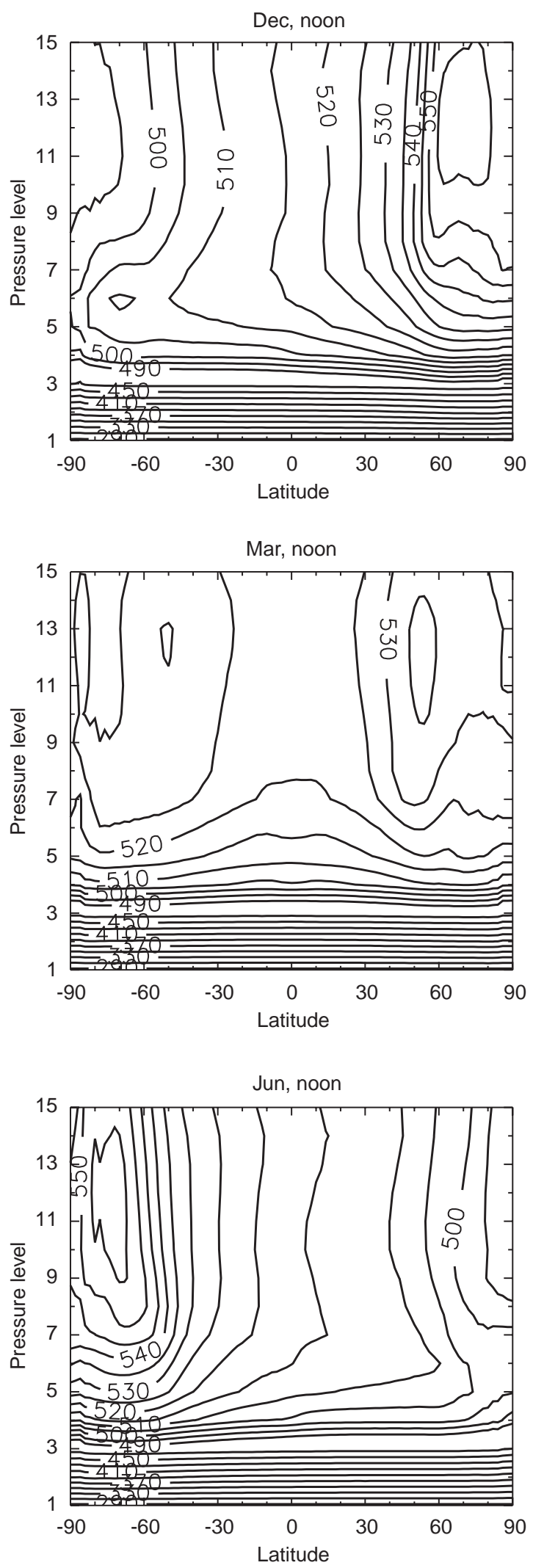

P-Parameter

$\mathrm{F} 10.7=100$

Long $=0 \mathrm{E}$
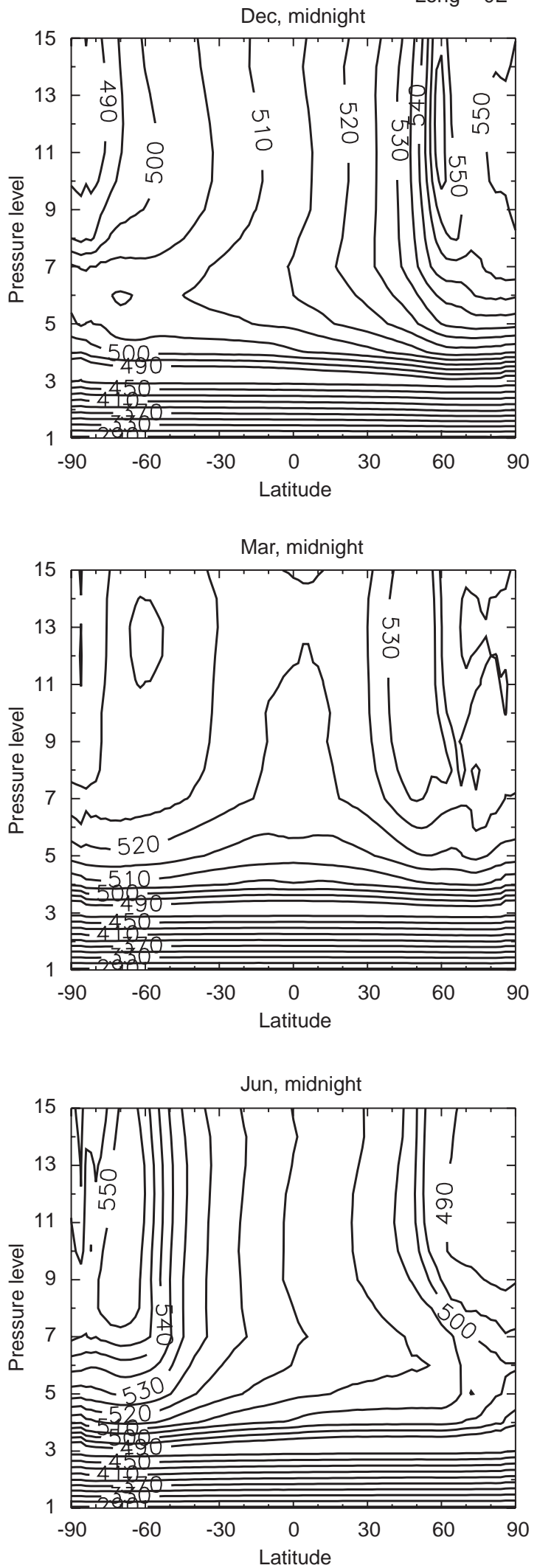

Fig. 4. Cross sections of $P$-parameter versus geographic latitude and pressure-level $Z$ at local noon and midnight, longitude $0^{\circ}$, for December, March and June. See Table 1 for the relation between pressure-level $Z$ and real height. Contour interval 5 units 

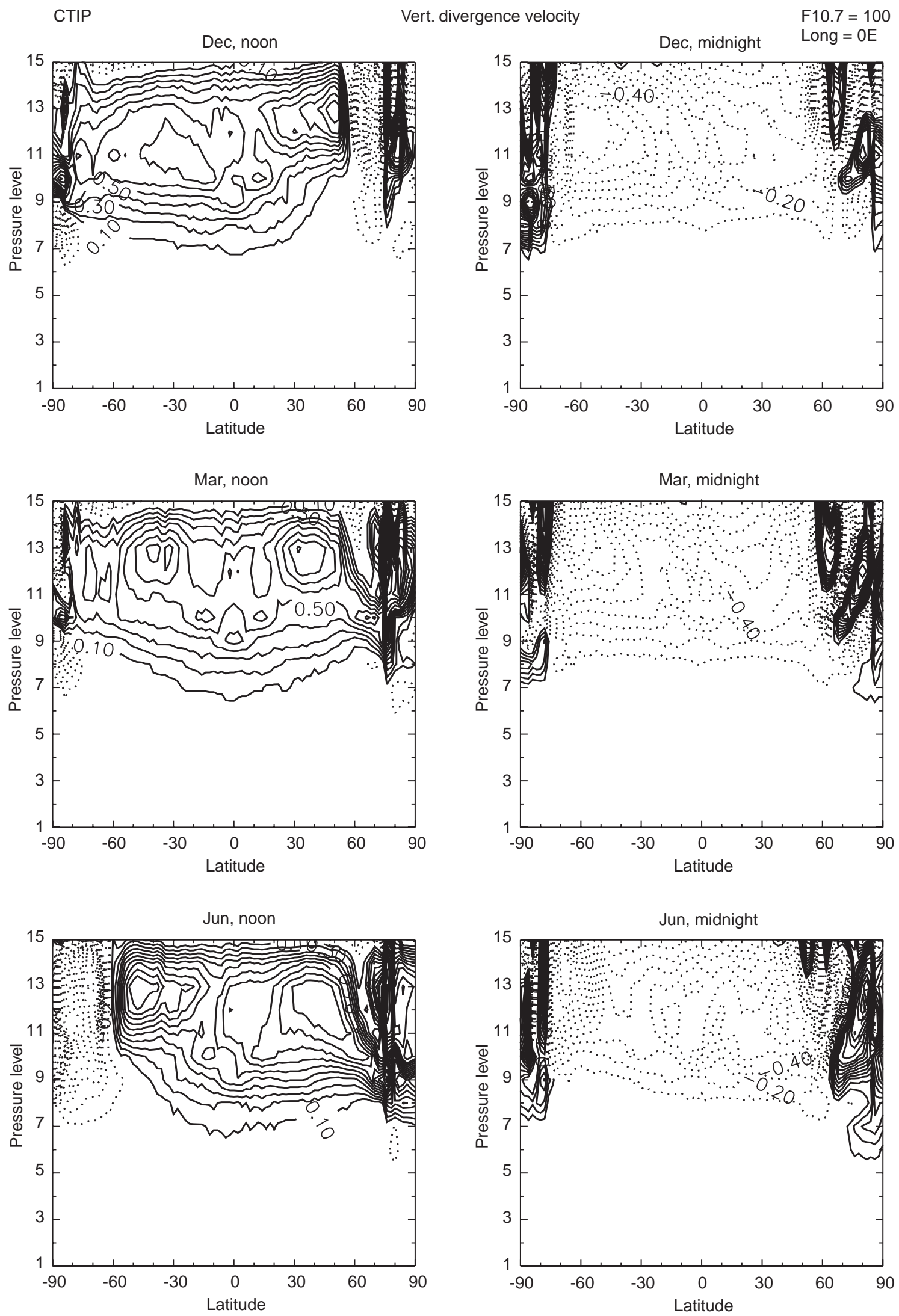

Fig. 5. Cross sections of divergence velocity $W_{\mathrm{D}}$ versus geographic latitude and pressure-level $Z$ at local noon and midnight, longitude $0^{\circ}$, for December, March and June. The contour interval is latitudes), the greatest upward values at noon are approximately $+1 \mathrm{~m} \mathrm{~s}^{-1}$, and the greatest downward values at midnight are approximately $-0.7 \mathrm{~m} \mathrm{~s}^{-1}$ 
the magnetic and geographic equators do not coincide, show some geomagnetic influence on the distribution of $P$. In high midlatitudes (i.e. equatorward of the auroral ovals), at latitudes $50^{\circ}-60^{\circ}$ in both hemispheres, $P$ is enhanced by $5-10$ units above its value at low latitudes and polar latitudes.

The March noon plot in Fig. 5 shows that the divergence velocity $W_{\mathrm{D}}$ is very small $\left(<0.1 \mathrm{~m} \mathrm{~s}^{-1}\right)$ below about pressure-level $Z=8(140 \mathrm{~km})$. Above this level $W_{\mathrm{D}}$ is upward, mostly in the range $0.5-1 \mathrm{~m} \mathrm{~s}^{-1}$; it varies slowly with height but is fairly constant in latitude, with broad maxima at $30^{\circ}-40^{\circ}$ in both hemispheres and complex structures in the auroral ovals (particularly the northern oval). At March midnight, $W_{\mathrm{D}}$ is downward (about -0.5 to $-1 \mathrm{~m} \mathrm{~s}^{-1}$ ) and nearly uniform with latitude, almost everywhere above $Z=8$, except for the complex structure in auroral latitudes. The amplitudes of $W_{\mathrm{D}}$ vary somewhat with longitude.

At solstice (top and bottom plots of Fig. 4), there are strong summer-to-winter gradients of $P$ both by day and night. Figure 4 shows that in summer $P$ becomes independent of height (i.e. the contours of $P(Z)$ become vertical) only above $Z=9$, at a height of $160 \mathrm{~km}$ or more. Models such as MSIS generally assume diffusive equilibrium exists above $120 \mathrm{~km}$ (corresponding to $Z=6.5$ in CTIP), but this assumption may introduce errors of $25 \%$ or more in model values of $\left[\mathrm{O} / \mathrm{N}_{2}\right]$ ratio at F2-layer heights, particularly in summer.

All the results shown in this study apply to fairly quiet geomagnetic conditions. Rishbeth et al. (1987) showed that larger vertical variations of $P$ occur under storm conditions, and the vertical distributions of individual constituents depart more from diffusive equilibrium than the examples shown here.

Another conclusion that may be drawn from Fig. 4 is that the electric fields near the magnetic equator, which produce the well-known 'fountain effect' and the F2layer equatorial anomaly, have no great effect on neutral composition. This is most easily seen on the March plots, which show that equatorial effects on $P$ are no more than 2 units. This implies that, as expected from theory (e.g. Dougherty, 1961), the electric field system cannot transfer enough energy to the neutral air at F2layer heights to produce significant upward motion, which might then affect the $\left[\mathrm{O} / \mathrm{N}_{2}\right]$ distribution.

\section{Discussion}

As noted in Sect. 4, the maxima and minima of $W_{\mathrm{D}}$, $\left[\mathrm{O} / \mathrm{N}_{2}\right]$ ratio and $N \mathrm{mF} 2$ are not closely related to one another. Besides the factors there mentioned, namely solar zenith angle and the equatorial anomaly, there are other possible reasons. First, thermospheric structure takes time to adjust to changing motions, so the effect of $W_{\mathrm{D}}$ on $\left[\mathrm{O} / \mathrm{N}_{2}\right]$ ratio is not immediate. The effect of this delay is difficult to evaluate, but it might be represented by a time-weighted integral with some decaying 'timeweighting' function $g(t)$, of the general form

$\left[\mathrm{O} / \mathrm{N}_{2}\right] \Leftrightarrow \int W_{\mathrm{D}}(t) g(t) \mathrm{d} t$
Second, Fig. 1 shows strong zonal winds, especially in the vicinity of the auroral ovals, so the $\left[\mathrm{O} / \mathrm{N}_{2}\right]$ ratio at any place depends to some extent on upwelling and downwelling at other longitudes. In this case, the integration implied by Eq. (11) becomes even more complicated, because it would have to follow the zonal and meridional motion of the air and would thus require a spatial 'cell-tracking' procedure, e.g. Burns et al. (1991).

The composition changes, though locally produced by vertical motions, are smoothed out by horizontal winds. As mentioned in Sect. 4, the global wind system shown in Fig. 1 has a summer-to-winter prevailing component at solstice, typically $30 \mathrm{~m} \mathrm{~s}^{-1}$ or $2700 \mathrm{~km}$ per day, which carries air from summer to winter midlatitudes in a few days. The prevailing zonal wind, also of order $30 \mathrm{~m} \mathrm{~s}^{-1}$, carries air from west to east in the winter hemisphere and east to west in the summer hemisphere. This movement of $2700 \mathrm{~km}$ per day represents about $30^{\circ}$ of longitude or two hours of local time, depending on latitude.

Although the prevailing winds determine the gross features of the distribution of $\left[\mathrm{O} / \mathrm{N}_{2}\right]$ ratio, the details depend also on the daily variations. The amplitudes of the meridional and zonal wind components are typically $50 \mathrm{~m} \mathrm{~s}^{-1}$, giving a daily excursion of order $800 \mathrm{~km}$. Although not negligible, this oscillation is smaller in scale than the daily summer-to-winter prevailing motion of $2700 \mathrm{~km}$. Near the auroral ovals, the zonal winds are larger and their effect on the transport of air may be quite important, as suggested in Sect. 4.

From a perusal of the results for intermediate months, it is found that the seasonal changes take place quite quickly around equinox, essentially between February and April, and between August and October. During the solstice seasons, conditions are fairly stable, except for midwinter reductions in $\mathrm{NmF} 2$, which are caused partly by the large solar zenith angle at high midlatitudes and partly by the strong poleward winds.

\section{Conclusion}

The modelling shows that upwelling of the neutral air, which lowers the neutral $\left[\mathrm{O} / \mathrm{N}_{2}\right]$ ratio, takes place over the sunlit thermosphere (and also locally in the auroral ovals). Downwelling, which raises the $\left[\mathrm{O} / \mathrm{N}_{2}\right]$ ratio, takes place mainly at night. Downwelling also takes place in the regions of sparse energy input, between the winter sunlit region and the daytime auroral ovals. These regions are broader and more extensive in 'farfrom-pole' longitudes (i.e. remote from the magnetic poles) than in 'near-pole' longitudes. Although the study is not primarily concerned with F-layer anomalies, its results should help to explain them.

Despite the large $\left[\mathrm{O} / \mathrm{N}_{2}\right]$ ratios they contain, the winter high latitude 'far-from-pole' areas (around latitudes $70^{\circ}-80^{\circ} \mathrm{N}$ at $90^{\circ} \mathrm{E}$ in December, and latitudes $70^{\circ}-$ $80^{\circ} \mathrm{S}$ at $90^{\circ} \mathrm{W}$ in June) have very low values of $\mathrm{NmF} 2$, because of the weakness or absence of sunlight. These oxygen-rich regions are likely to be more pronounced in 
theoretical models than in the real ionosphere. Codrescu (private communication) finds that, when the natural variability of the high latitude energy inputs is taken into account, the latitude variation of $\left[\mathrm{O} / \mathrm{N}_{2}\right]$ ratio in these sectors is much less striking than in the CTIP model results. Nevertheless, the CTIP model predicts that large values of $\left[\mathrm{O} / \mathrm{N}_{2}\right]$ ratio ought to be detectable by satellite-borne instruments in these zones.

The patterns of $N \mathrm{mF} 2$ and $\left[\mathrm{O} / \mathrm{N}_{2}\right]$ ratio do not seem sensitive to solar activity. They are almost the same for $F_{10.7}=180$ as for the value $F_{10.7}=100$ illustrated in this work, though with numerical differences. Further investigation is needed of the effects of magnetic disturbance, and of tides and waves transmitted from the middle atmosphere.

Acknowledgements. This research was made possible by the work of L. Zou in running the CTIP model. It was supported financially by the UK Natural Environment Research Council under the Antarctic Special Topic (AST-4) SWIMS programme. CTIP is a collaborative project between the Atmospheric Physics Laboratory of University College London, the School of Mathematics and Statistics of the University of Sheffield, and the NOAA Space Environment Center, Boulder, Colorado.

Topical Editor F. Vial thanks C. Fesen for her help in evaluating this paper.

\section{Appendix}

For any gas (molecular mass $M$ ) the concentration $n$ varies with real height $h$ as

$n_{h}=\frac{n_{0} T_{0}}{T_{h}} \cdot \exp \left[-\int_{h_{0}}^{h} \frac{\mathrm{d} h}{H}\right]=\frac{n_{0} T_{0}}{T_{h}} \mathrm{e}^{-z}$

where $n_{0}$ and $T_{0}$ are the concentration and temperature at the base height $h_{0}$, and $n_{h}$ and $T_{h}$ are the concentration and temperature at any height $h$ above $h_{0}$, and $Z$ is the reduced height as defined in Sect. 2.1 (but taking the height $h_{0}$ to be $Z=0$, instead of $Z=1$ as in CTIP, see Eqs. 2 and 3).

For two or more individual gases $1,2, \ldots$, in diffusive equilibrium, the reduced heights $Z_{1}, Z_{2}, \ldots$ may be defined thus:

$Z_{1}(h)=\int_{h_{0}}^{h} \frac{\mathrm{d} h}{H_{1}}, \quad Z_{2}(h)=\int_{h_{0}}^{h} \frac{\mathrm{d} h}{H_{2}}$

It may be assumed that all neutral gases $1,2, \ldots$ are at the same temperature, $T$. Recall that for any gas $(j)$ the scale height $H_{j}=k T / M_{j} g$ (where $k=$ Boltzmann's constant). Although the argument holds equally for any number of gases, consider just two gases 1,2 . Then at all heights $h>h_{0}$ :

$\frac{Z_{1}}{Z_{2}}=\frac{H_{2}}{H_{1}}=\frac{M_{1}}{M_{2}}$

because, in Eq. (13) that define $Z_{1}$ and $Z_{2}$, the only difference is in the molar masses $M_{1}$ and $M_{2}$. Using $n_{0,1}$ and $n_{0,2}$ to denote concentrations at the base level $h_{0}$, the pressure at this level is

$p_{0}=\left(n_{0,1}+n_{0,2}\right) \cdot k T_{0}$

and using Eq. (12), the pressure $p_{h}$ at any higher level $h$ is

$$
\begin{aligned}
p_{h} & =p_{h, 1}+p_{h, 2} \\
& =\left(n_{h, 1}+n_{h, 2}\right) \cdot k T_{h}=\left(n_{0,1} \mathrm{e}^{-Z_{1}}+n_{0,2} \mathrm{e}^{-Z_{2}}\right) \cdot \frac{T_{0}}{T_{h}} k T_{h}
\end{aligned}
$$

Any particular value of pressure $p\left(=p_{1}+p_{2}\right)$ is characterized by its particular values $Z_{1}$ and $Z_{2}$. Now suppose the temperature profile $T(h)$ changes in any arbitrary way. The real height $h$ of this pressure-level will change, in accordance with Eq. (3) (but again neglecting the ' 1 '). Irrespective of how $T$ varies, the concentration ratio of gases 1 and 2 at this constant pressure level is given by

$\frac{n_{h, 1}}{n_{h, 2}}=\frac{n_{0,1}}{n_{0,2}} \mathrm{e}^{Z_{2}-Z_{1}}=\frac{n_{0,1}}{n_{0,2}} \mathrm{e}^{z_{2}\left(\frac{M_{2}-M_{1}}{M_{2}}\right)}$

Since $\left(M_{2}-M_{1}\right) / M_{2}$ is a constant, it follows that the ratio $n_{1} / n_{2}$ remains constant at any fixed value or pressure $p=p_{1}+p_{2}$, provided the ratio $n_{0,1} / n_{0,2}$ is constant. The same holds for any number of gases. In other words, provided the composition remains fixed at the base level $h_{0}$, the composition at any other fixed pressure-level also remains fixed, so long as the gases are in diffusive equilibrium.

\section{References}

Burns, A. G., T. L. Killeen, and R. G. Roble, A simulation of thermospheric composition changes during an impulse storm, J. Geophys. Res., 96, 14153-14167, 1991.

Dickinson, R. E., and J. E. Geisler, Vertical motion field in the middle thermosphere from satellite drag densities, Mon. Weather Rev., 96, 606-616, 1968.

Dougherty, J. P., On the influence of horizontal motion of the neutral air on the diffusion equation of the F-region, J. Atmos. Terr. Phys., 20, 167-176, 1961.

Duncan, R. A., F-region seasonal and magnetic storm behaviour, J. Atmos. Terr. Phys., 31, 59-70, 1969.

Field, P. R., H. Rishbeth, R. J. Moffett, D. W. Idenden, T. J. FullerRowell, G. H. Millward, and A. D. Aylward, Modelling composition changes in F-layer storms, J. Atmos. Solar-Terr. Phys., 60, 523-543, 1998.

Foster, J. C., J. M. Holt, R. G. Musgrove, and D. S. Evans, Ionospheric convection associated with discrete levels of particle precipitation, Geophys. Res. Lett., 13, 656-659, 1986.

Fuller-Rowell, T. J., and D. Rees, Derivation of a conservation equation for mean molecular weight for a two-constituent gas within a three-dimensional, time-dependent model of the thermosphere, Planet. Space Sci., 31, 1209-1222, 1983.

Fuller-Rowell, T. J., and D. S. Evans, Height-integrated Pedersen and Hall conductivity patterns inferred from the TIROSNOAA satellite data, J. Geophys. Res., 92, 7606-7618, 1987.

Fuller-Rowell, T. J., D. Rees, S. Quegan, R. J. Moffett, M. V. Codrescu, and G. H. Millward, A coupled thermosphereionosphere model (CTIM), in STEP Handbook of Ionospheric Models Ed. R. W. Schunk, Utah State University, Logan, Utah, pp. 217-238, 1996. 
Garriott, O. K., and H. Rishbeth, Effects of temperature changes on the electron density profile in the F2-layer, Planet. Space Sci., 11, 587-590, 1963.

Hedin A. E., MSIS-86 thermospheric model, J. Geophys. Res., 92, 4649-4662, 1987.

Johnson, F. S., Composition changes in the upper atmosphere, in Electron density distributions in the ionosphere and exosphere, Ed. E. Thrane. North-Holland, Amsterdam, pp. 81-84, 1964.

King, G. A. M., The dissociation of oxygen and high level circulation in the atmosphere, J. Atmos. Sci., 21, 231-237, 1964.

Millward, G. H., H. Rishbeth, R. J. Moffett, S. Quegan, and T. J. Fuller-Rowell, Ionospheric F2-layer seasonal and semiannual variations, J. Geophys. Res., 101, 5149-5156, 1996a.

Millward, G. H., R. J. Moffett, S. Quegan, and T. J. Fuller-Rowell, A coupled thermosphere-ionosphere-plasmasphere model (CTIP), in STEP Handbook of Ionospheric Models, Ed. R. W. Schunk, Utah State University, Logan, Utah, pp. 239-280, 1996b.

Richmond, A. D., M. Blanc, B. A. Emery, R. H. Wand, B. G. Fejer, R. F. Woodman, S. Ganguly, P. Amayenc, R. A. Behnke, C. Calderon, and J. V. Evans, An empirical model of quiet-day electric fields at middle and low latitudes, J. Geophys. Res., 85, 4658-4664, 1980.
Rishbeth, H., How the thermospheric circulation affects the ionospheric F2-layer, J. Atmos. Solar-Terr. Phys., 60, 1385-1402, 1998.

Rishbeth, H., and C. S. G. K. Setty, The F-layer at sunrise, J. Atmos. Terr. Phys., 21, 263-276, 1961.

Rishbeth, H., R. J. Moffett, and G. J. Bailey, Continuity of air motion in the mid-latitude thermosphere, J. Atmos. Solar-Terr. Phys., 31, 1035-1047, 1969.

Rishbeth, H., T. J. Fuller-Rowell, and D. Rees, Diffusive equilibrium and vertical motion in the thermosphere during a severe magnetic storm: a computational study, Planet. Space Sci., 35, 1157-1165, 1987.

Shimazaki, T., Effects of vertical mass motions on the composition structure in the thermosphere, Space Res., 12, 1039-1045, 1972.

Torr, M. R., and D. G. Torr, The seasonal behaviour of the F2layer of the ionosphere, J. Atmos. Terr. Phys., 35, 2237-2251, 1973.

Yonezawa, T., and Y. Arima, On the seasonal and non-seasonal annual variations and the semi-annual variation in the noon and midnight electron densities of the F2-layer in middle latitudes, J. Radio Res. Labs., 6, 293-309, 1959. 